\title{
Predictors of couple HIV counseling and testing among adult residents of Bukomero sub-county, Kiboga district, rural Uganda
}

Richard Muhindo ${ }^{1 *}$, Annet Nakalega ${ }^{2}$ and Joyce Nankumbi ${ }^{1}$

\begin{abstract}
Background: Studies have shown that couple HIV counseling and testing (CHCT) increased rates of sero-status disclosure and adoption of safer sexual behaviors with better linkage to treatment and care. However, current evidence suggests that new HIV infections are occurring among heterosexual couples in stable relationships where the majority of the individuals are not aware of their partner's serostatus. This study examined the predictors of CHCT uptake among married or cohabiting couples of Bukomero sub-county Kiboga district in Uganda.
\end{abstract}

Methods: This cross-sectional correlational study was conducted among 323 individuals who were either married or cohabiting, aged 18-49 years. Participants were enrolled from randomly selected households in Bukomero sub-county. Data were collected using an interviewer-administered questionnaire on socio-demographics, self-rating on awareness of CHCT benefits, couple discussion about HIV testing and CHCT practices. Couples were compared between those who had reported to have tested as a couple and those who had not. Binary logistic regression was performed to determine the adjusted odds ratio [aOR] and $95 \%$ confidence intervals [Cl] for CHCT uptake and the other independent variables.

Results: Of the participants 288 (89.2 \%) reported to have ever taken an HIV test only 99 (34.4\%) did so as a couple. The predictors of testing for HIV as a couple were discussing CHCT with the partner (adjusted odds ratio 4.95[aOR], $95 \%$ confidence interval [Cl]:1.99-12.98; $p<0.001$ ), awareness of CHCT benefits (aOR 3.23; $95 \% \mathrm{Cl} 1.78-5.87 ; p<0.001$ ) and having time to test as a couple (aOR 2.61; $95 \% \mathrm{Cl} 1.22-5.61 ; p<0.05)$.

Conclusion: Uptake of HIV counseling and testing among couples was low. Discussing CHCT with partner, awareness of CHCT benefits, and availability of time to test as a couple were predictive of CHCT uptake. Thus CHCT campaigns should emphasize communication and discussion of HIV counseling and testing among partners.

Keywords: Predictors, Couple HIV Counseling and Testing, Rural Uganda

\section{Background}

Uganda is one of two sub-Saharan African countries where the number of new HIV infection increased between 2005 and 2013 [1]. Of the 1.5,000 000 new HIV infections posted by the region in 2013, nearly $48 \%$ were contributed by Uganda, South Africa and Nigeria [1]. Similar findings were reported in a national Ugandan survey where the proportion of the adult population living with HIV increased from $6.4 \%$ in 2005 to $7.3 \%$ in $2011[2,3]$. Of the reported 130,000 new HIV infections

\footnotetext{
* Correspondence: r.muhindo@yahoo.com

'Department of Nursing, College of Health Sciences, Makerere University, P.O Box 7072, Kampala, Uganda

Full list of author information is available at the end of the article
}

in 2009 in Uganda, 43 \% occurred in serodiscordant couples [4-7]. Studies evaluating the effectiveness of preventive interventions in discordant couples have shown that up to $80 \%$ of new infections could be prevented by consistent condom use, $54 \%$ from circumcision in negative male partners, $71 \%$ from post exposure prophylaxis (PrEP), and $96 \%$ from use of antiretroviral therapy (ART) by the HIV infected individuals [4, 8-15].

In efforts to reduce the number of new infections, Uganda has adopted a combination of HIV prevention approaches. The plan is to promote and scale up interventions both biomedical (ART, PrEP, male circumcision, and HIV counseling and testing) and behavioral change (condom use, and reduction in number of sexual 
partners), and also to address the structural drivers of HIV [16]. The current strategy highlights priority prevention interventions for particular categories of individuals, and specifically discordant couples with the importance of linking them into HIV care [16]. Current estimates indicate that $6 \%$ of the couples in Uganda are discordant and that $43 \%$ of the new infections that occurred in 2008 were among mutually monogamous heterosexual couples where many did not know their partner's HIV status [3, 7]. Raising the levels of mutual HIV sero-status awareness among discordant couples could ultimately impact the proportion enrolled into care and prevention.

Couple HIV counseling and testing (CHCT) uptake is an important entry into HIV care and prevention [17-19]. CHCT is thus a key link to combination prevention interventions with ART, PrEP and male circumcision. CHCT is associated with partner disclosure and adoption of safer sexual practices [20-24]. When couples are tested together the burden of disclosure is reduced [25]. Nondisclosure of a positive sero-status was common among couples when either member went alone for testing [26, 27]. This is a drawback in the fight against HIV/AIDS especially when new infections are occurring in stable heterosexual relationships [27]. Knowledge of partner's sero-status increased chances of being enrolled into HIV care and adoption of safe sex practices including condom use [28-30].

Emerging evidence indicates that up to three-quarters of new HIV infections could be prevented by couple HIV counseling and testing [31-34]. For concordant negative couples (both partners HIV negative), CHCT is important in the adoption of risk-reduction behaviors. It's also important for concordant positive couples so that they can access available family planning, social services, treatment programs and safe child bearing. Further, CHCT is important to discordant couples, partners with different HIV status, to prevent HIV transmission to the uninfected partners, for social support and for treatment of the infected person. HIV testing is widely available in Uganda at stand alone voluntary counseling and testing (VCT) clinics, health centers and hospitals. However, despite the benefits associated with CHCT, few couples have mutually disclosed their HIV sero-status. Our study sought to determine the predictors of $\mathrm{CHCT}$ uptake among residents of Bukomero sub-county, Kiboga district. The district is located in the central part of the country where there is high discordance [3].

\section{Methods}

\section{Study design and setting}

A cross-sectional study was conducted in Bukomero sub-county between February and March, 2013. The sub-county is found in Kiboga a rural district in Central Uganda. The district has a population of 148,606 people with a third living in Bukomero [35].

\section{Study population and data collection procedures}

The study participants included adult men or women aged 18-49 years who were either married or cohabiting for not less than 6 months at the time of data collection. Participants were recruited from randomly selected households in the four parishes of Bukomero. If the woman and man were both present in the household, they were interviewed as a couple. A structured self-report interview was used to collect data. The questionnaire was pretested on 20 adults who were married from Nangabo Sub-county in Wakiso district in January 2013. Adjustments were made to clarify some questionnaire items.

\section{Statistical analysis}

In this study, testing for HIV as a couple, the primary outcome of interest was defined as whether a man or a woman in the current relationship had ever sought CHCT. It was measured on a dichotomous scale of "Yes" and "No". The three major independent variables were the discussion of CHCT with the partner, perceived awareness of CHCT benefits, and willingness to go for CHCT. Discussing $\mathrm{CHCT}$ with the partner was defined as whether there were conversations about the need and benefits of CHCT. It was measured on a three point rank scale from very often to rare. Perceived awareness of CHCT benefits was defined by the participant's self-evaluation of awareness of CHCT benefits. It was measured on a five point likert scale from strongly agree to strongly disagree. Participants were also asked to indicate whether they were or were not willing to go for CHCT.

Demographic data was collected on the duration of the relationship, nature of the co-habitation of the relationship (stay together under one roof or occasionally see each other), and having enough time as a couple to go for HIV counseling and testing. Others variables included religion, level of education and their perception of their participation in gainful work.

Statistical analysis included contingency tables and binary logistic regression. The three major independent variables were assessed using ordinal level of measurement and dichotomized during analysis. For perceived awareness of CHCT benefits, participants who rated themselves to be aware of $\mathrm{CHCT}$ benefits by selecting strongly agree or agree were considered to score high and those who selected strongly disagree, disagree or neutral were considered as unaware and were scored low. Contingency tables and correlation index procedures, association between outcome reference variable, testing for HIV as a couple and independent variables were examined. Variables that showed significant association in unavariable analysis $(p<.05)$ with the outcome variable were further analyzed using binary logistic regression, a technique used to describe association between categorical outcome variable with categorical 
independent variables [36]. Individual odds and adjusted odds for the independent variables were determined. Analyses were performed using SPSS version 17.0.

\section{Ethical considerations}

The study was approved by the Makerere University School of Health Sciences Institutional Review Board. All participants in the study provided written informed consent.

\section{Results}

\section{Socio-demographic characteristics}

The study enrolled 323 male and female participants who were married or cohabiting for a minimum of six months at the time of data collection. The median age of the participants was 25 years and the majority 240 (74.\%) were females. High number of females was probably due to the time of day of the data collection when only the women were most likely to be home. Half the respondents 174 (54\%) had obtained a secondary education or higher, and 319 (99 \%) were living as couples under one roof. The median duration of the current relationship was 4 years with 154 (48\%) reporting having been in relationship for more than 4 years. The majority $244(75 \%)$ reported discussing CHCT with their partner, 271 (84 \%) reported willing to go for $\mathrm{CHCT}$, and $129(40 \%)$ rated themselves low on awareness of CHCT benefits (see Table 1). Despite 253 (79\%) respondents reporting they had time as a couple to go for CHCT and 288 (89\%) had ever tested for HIV, only 99 (34 \%) did so as a couple. The commonly cited reasons for participating in CHCT included: wanting to get married $99(54 \%)$, request during antenatal care 50 (27 \%) and desire to know their HIV status 34 (19\%). Among the 99 respondents who tested as couples, 64 (65\%) had tested within the last year.

\section{Association between $\mathrm{CHCT}$ and independent variables}

Bivariate analysis showed that there were significant statistical associations between discussed CHCT with partner $(p<0.001)$, perceived awareness of the CHCT benefits $(p<0.001)$, had time as couple for CHCT $(p \leq 0.001)$, were willing to go for CHCT $(p<0.009)$, duration of the relationship $(p<0.04)$ and participating in CHCT (see Table 2). Among the 99 participants who reported to have tested as a couple, 93 were identified as talking very often about $\mathrm{CHCT}$ within the relationship, 80 rated themselves high on self-perceived awareness of the benefits of CHCT, 89 reported having time as a couple for CHCT, 95 were willing to go for CHCT, and 62 were in the relationship of less than four years. Other variables such as education and religion showed no significant statistical association. Further, there was a significant statistical association between discussing CHCT with partner and perceived awareness of the CHCT benefits $(p<.002)$.
Table 1 Socio-demographic characteristics $(N=323)$

\begin{tabular}{|c|c|c|c|}
\hline Variables & Frequency (\%) & Median & $\begin{array}{l}\text { Interquartile } \\
\text { range }\end{array}$ \\
\hline Age & & 25 years & 10 years \\
\hline \multicolumn{4}{|l|}{ Gender } \\
\hline Female & $240(74)$ & & \\
\hline Male & $83(26)$ & & \\
\hline \multicolumn{4}{|l|}{ Nature of relationship } \\
\hline $\begin{array}{l}\text { Staying together } \\
\text { under one roof }\end{array}$ & $319(98.8)$ & & \\
\hline See each other occasionally & $4(1.2)$ & & \\
\hline \multicolumn{4}{|l|}{ Religion } \\
\hline Christian & $269(8.3)$ & & \\
\hline Muslim & $54(16.7)$ & & \\
\hline \multicolumn{4}{|l|}{ Education level } \\
\hline $\begin{array}{l}\text { Primary or no formal } \\
\text { education }\end{array}$ & $149(46)$ & & \\
\hline Secondary and above & $174(54)$ & & \\
\hline \multicolumn{4}{|l|}{ Duration in the relationship } \\
\hline Less than 4 years & $169(52)$ & 4 years & 8 years \\
\hline Greater than 4 years & $154(48)$ & & \\
\hline \multicolumn{4}{|l|}{ Ever tested for HIV } \\
\hline Yes & $288(89)$ & & \\
\hline No & $35(11)$ & & \\
\hline \multicolumn{4}{|c|}{ Talking about CHCT in the relationship } \\
\hline Very often & $244(76)$ & & \\
\hline Rarely & $79(24)$ & & \\
\hline \multicolumn{4}{|c|}{ Percieved awareness of the $\mathrm{CHCT}$ benefits } \\
\hline High & $194(60)$ & & \\
\hline Low & $129(40)$ & & \\
\hline \multicolumn{4}{|l|}{ Last time tested asa couple } \\
\hline within the last year & $64(65)$ & & \\
\hline within the last 2 years & $20(20)$ & & \\
\hline More than 3 years & $15(15)$ & & \\
\hline
\end{tabular}

Likewise, $65 \%$ of those who reported discussing CHCT with partner also rated themselves high on perceived awareness of the CHCT benefits, $82 \%$ indicated having time as a couple for CHCT while $93.4 \%$ were willing to go for CHCT.

\section{Predictors of couple HIV counseling and testing (CHCT)}

In the univariable analysis discussion of $\mathrm{CHCT}$ with their partner, awareness of the benefits of couple counseling and having time for $\mathrm{CHCT}$ were significantly associated with testing for HIV as a couple (see Table 3 ). The adjusted odds ratios for $\mathrm{CHCT}$ predictors were: discussion of CHCT with the partner (adjusted odds ratio 4.95[aOR]; $95 \%$ confidence interval [CI]:1.99- 
Table 2 Associations between $\mathrm{CHCT}$ and independent variables $(N=288)$

\begin{tabular}{|c|c|c|c|}
\hline \multirow[t]{2}{*}{ Variable } & Yes & No & \multirow[t]{2}{*}{$P$-value } \\
\hline & $(N=99)$ & $N(189)$ & \\
\hline Religion & & & .250 \\
\hline Christians & $87(35 \%)$ & $159(65 \%)$ & \\
\hline Muslim & $12(29 \%)$ & $30(71 \%)$ & \\
\hline Level of education & & & .419 \\
\hline Primary or no formal education & $46(35 \%)$ & $84(65 \%)$ & \\
\hline Secondary and above & $53(34 \%)$ & $105(67 \%)$ & \\
\hline Duration in relationship & & & $.04^{*}$ \\
\hline Less than 4 years & $62(39 \%)$ & $96(61 \%)$ & \\
\hline Talking about $\mathrm{CHCT}$ in the relationship & & & $.001^{*}$ \\
\hline Most often & $93(39.9)$ & $140(60.1)$ & \\
\hline Rarely & $6(10.9)$ & $49(89.1)$ & \\
\hline Perceived awareness of $\mathrm{CHCT}$ benefits & & & $.001^{*}$ \\
\hline High awareness & $80(43.0)$ & $106(57.0)$ & \\
\hline Low awareness & 19 (18.6) & $83(81.4)$ & \\
\hline Have time as couple for $\mathrm{CHCT}$ & & & $.001^{*}$ \\
\hline Yes & $89(39.0)$ & $139(61.0)$ & \\
\hline No & $10(16.7)$ & $50(83.3)$ & \\
\hline Willingness to go for $\mathrm{CHCT}$ & & & $.009^{*}$ \\
\hline Yes & $95(36.7)$ & $164(63.3)$ & \\
\hline No & $4(13.8)$ & $25(86.2)$ & \\
\hline
\end{tabular}

*Statistically significant variables at $P<0.05$

12.98; $p<0.001$ ), awareness of CHCT benefits (aOR $3.23 ; 95 \%$ CI $1.78-5.87 ; p<0.001)$ and had time to test as a couple (aOR 2.61; $95 \%$ CI 1.22-5.61; $p<0.05)$.

\section{Discussion}

This study focused on predictors of couple HIV counseling and testing (CHCT) of married or cohabiting men and women. The findings of the study show that 9 in 10 of the participants had ever taken an HIV test and 3 in 10 had tested for HIV as a couple. The predictors of $\mathrm{CHCT}$ were; discussion of CHCT with the partner, awareness of $\mathrm{CHCT}$ benefits and had time for CHCT.

In Uganda CHCT is highlighted as one of the key linkages to HIV care, treatment and prevention [37]. CHCT is particularly important because it reduces the burden of sharing one's HIV positive status, provides a built-in support system which may aid in linking individuals with HIV to essential care and treatment services. This is important for discordant couples for which antiretroviral therapy may significantly reduce the risk of transmission $[20,38-40]$.

Our current findings, however, indicate that despite high (84 \%) reported willingness to go for CHCT, uptake is still low. This demonstrates the intention-behavioral gap observed in a number of behavioral studies. For example some studies evaluating condom use have shown that up to $50 \%$ of those who intend to use condoms never used them $[41,42]$. Among the most frequent cited reasons for testing as a couple were; wanting to get married, meeting a request during antenatal care and desiring to know HIV status. In this study we found that couples who discussed CHCT with their partner were almost 5 times more likely to take an HIV test as a couple compared to those who did not. Discussing CHCT with partner could probably help couples reflects on the benefits of HIV testing, but also build their confidence and self-efficacy in confronting the challenges associated with disclosure and acceptance of results.

The findings of the study are similar to studies conducted in Nigeria, Mozambique and eastern Uganda in which low rates of couple HIV testing were reported [43-47]. While studies conducted in Zambia, Kenya and Tanzania demonstrated increased CHCT uptake when using a home-based approaches [48-53], this approach has not been scaled up in Uganda. Other studies have also established discussing CHCT with their partner, awareness of CHCT benefits and having time for $\mathrm{CHCT}$ as predictors of couple HIV testing. For example studies conducted in South Africa and Uganda established that sexual communication and prior CHCT discussion among partners was a strong predictor of taking an HIV test as a couple [43, 54]. Similarly, CHCT studies in Thailand, USA, Cameroon, Dominican Republic, Georgia and India among pregnant mothers and their partners have found similar results [55]. In a study on HIV self-testing in Nigeria awareness of CHCT benefits was associated with HIV testing [56]. Similar findings were identified in studies conducted in Northern Tanzania and South Africa [48, 57].

There are some study limitations related to the design and representativeness. The participants were recruited from Bukomera sub-county and as such may not be

Table 3 Predictors of couple HIV counseling and testing; multivariate analysis

\begin{tabular}{lllll}
\hline Variable & Odds Ratio $(95 \% \mathrm{Cl})$ & $p$-value & Adjusted Odds ratio $(95 \% \mathrm{Cl})$ & $p$-value \\
\hline Duration in a relationship (< or $>4$ years) & $1.62(.99-2.67)$ & .056 & $1.39(.81-2.38)$ & .230 \\
Discussing CHCT with partner & $5.43(2.23-13.18)$ & .001 & $3.23(1.78-5.87)$ & .001 \\
Awareness of CHCT benefits & $3.28(1.85-5.87)$ & .001 & $1.72(.52-5.69)$ & .001 \\
Willingness to go for CHCT & $3.62(1.22-10.72)$ & .020 & $2.61(1.22-5.61)$ & .374 \\
Having time as a couple for CHCT & $3.20(1.54-6.64)$ & .002 & .014 \\
\hline
\end{tabular}


representative of the whole district. The study design was cross-sectional, and the findings could differ over a period of time. A longitudinal prospective study with a larger sample could provide a more complete understanding of the predictors of couples' participation in CHCT.

However, our findings do support the model that partner communication and their awareness of $\mathrm{CHCT}$ benefits increases the chances of HIV counseling and testing among couples. Promoting couple communication on HIV testing should be key in CHCT promotional campaigns and programs.

\section{Conclusion}

Uptake CHCT was low among heterosexual couples in a rural Ugandan setting and was significantly positively associated with discussion of CHCT with partner, awareness of CHCT benefits and reported availability of time. Our findings suggest that to increase HIV testing among couples, promotional campaigns should emphasize discussion of CHCT with partners.

\begin{abstract}
Abbreviations
AIC: Aids Information Center; AIDS: Acquired Immune Deficiency Syndrome; CHCT: Couple HIV Counseling and Testing; CVCT: Couple Voluntary Counseling and Testing; HCT: HIV Counseling and Testing; HIV: Human Immunodeficiency Virus; MOH: Ministry of Health; MSM: Men who have sex with Men; PMTCT: Prevention of Mother -to- Child Transmission; UAIS: Uganda Aids Indicator Survey; UNAIDS: The Joint United Nations Programme on HIV/AIDS; UNGASS: United Nations General Assembly Special Session on HIV/AIDS; VCT: Voluntary Counseling and Testing; VHCT: Voluntary HIV Counseling and Testing; WHO: World Health Organization..
\end{abstract}

\section{Competing interests}

The authors in this study have no conflict of interest.

\section{Authors' contributions}

MR conceived and refined the research idea, participated in the design of the study, performed the statistical analysis, and drafting of the manuscript NA coordinated data collection.

$\mathrm{JN}$ participated in drafting and writing of the manuscript. All authors read and approved the final manuscript.

\section{Acknowledgements}

We would like to thank the local leadership of Bukomero Sub-county and Kiboga District that enabled the data collection process. Also we would like to thank Associate Professor Sara groves and Dr. Wendy Green who made the English edits.

\section{Author details}

'Department of Nursing, College of Health Sciences, Makerere University, P.O Box 7072, Kampala, Uganda. ${ }^{2}$ Mulago National Referral Hospital, Kampala, Uganda.

Received: 18 February 2015 Accepted: 18 November 2015 Published online: 24 November 2015

\section{References}

1. HIV/AIDS JUNPo. The Gap Report. UNAIDS website. 2014.

2. Commission UA. HIV and AIDS Uganda Country Progress Report, 2013. Kampala, Uganda: Uganda AIDS Commission; 2013.

3. Uganda A. Indicator Survey 2011. Demographic and Health Surveys, ICF International 2012. http://health.go.ug/docs/UAIS_2011_KEY_FINDINGS.pdf.
4. Gouws E, Cuchi P. Focusing the HIV response through estimating the major modes of HIV transmission: a multi-country analysis. Sex Transm Infect. 2012;88 Suppl 2:176-85.

5. Biraro S, Ruzagira E, Kamali A, Whitworth J, Grosskurth H, Weiss HA. HIV-1 transmission within marriage in rural Uganda: a longitudinal study. PLoS One. 2013;8(2):e55060

6. Kazooba P, Kasamba I, Baisley K, Mayanja BN, Maher D. Access to, and uptake of, antiretroviral therapy in a developing country with high HIV prevalence: a population-based cohort study in rural Uganda, 2004-2008. Tropical Med Int Health. 2012;17(8):e49-57.

7. Commission UA. Uganda HIV Modes of Transimission and Prevention Response Analysis. 2009.

8. Baeten JM, Donnell D, Ndase P, Mugo NR, Campbell JD, Wangisi J, et al. Antiretroviral prophylaxis for HIV prevention in heterosexual men and women. N Engl J Med. 2012;367(5):399-410.

9. Lasry A, Sansom SL, Wolitski RJ, Green TA, Borkowf CB, Patel P, et al. HIV sexual transmission risk among serodiscordant couples: assessing the effects of combining prevention strategies. AIDS. 2014;28(10):1521-9.

10. Van Damme L, Corneli A, Ahmed K, Agot K, Lombaard J, Kapiga S, et al. Preexposure prophylaxis for HIV infection among African women. N Engl J Med. 2012;367(5):411-22

11. Cohen MS, Chen YQ, McCauley M, Gamble T, Hosseinipour MC, Kumarasamy $\mathrm{N}$, et al. Prevention of HIV-1 infection with early antiretroviral therapy. N Engl J Med. 2011;365(6):493-505.

12. Cohen MS, Baden LR. Preexposure prophylaxis for HIV—where do we go from here? N Engl J Med. 2012;367(5):459-61.

13. Baggaley RF, White RG, Hollingsworth TD, Boily M-C. Heterosexual HIV-1 infectiousness and antiretroviral use: systematic review of prospective studies of discordant couples. Epidemiol (Cambridge, Mass). 2013;24(1):110.

14. Curran K, Baeten JM, Coates TJ, Kurth A, Mugo NR, Celum C. HIV-1 prevention for HIV-1 serodiscordant couples. Current HIV/AIDS Reports. 2012;9(2):160-70.

15. Gray R, Victor Ssempijja V, Shelton J, Serwadda D, Nalugoda F, Kagaayi J, et al. The contribution of HIV-discordant relationships to new HIV infections in Rakai, Uganda. AIDS (London, England). 2011;25(6):863.

16. $\mathrm{MOH}$. The National HIV Prevention Strategy for Uganda 2011-15. 2011.

17. Rwanyonga R, Abaasa A, Asiki G, Twefeho B, Bahemuka U, Aling E, et al. The "Worried Well" Among Clients Attending HIV/AIDS Counselling and Testing Services at a Clinical Research Centre in SW Uganda. AIDS Res Hum Retrovir. 2014;30(S1):A113-4.

18. Kilembe W, Wall KM, Mokgoro M, Mwaanga A, Dissen E, Kamusoko M, et al. Implementation of couples' voluntary HIV counseling and testing services in Durban, South Africa. BMC Public Health. 2015;15(1):601.

19. Wachira J, Kimaiyo S, Ndege S, Mamlin J, Braitstein P. What is the impact of home-based HIV counseling and testing on the clinical status of newly enrolled adults in a large HIV care program in Western Kenya? Clin Infect Dis. 2012;54(2):275-81.

20. Rosenberg NE, Pettifor AE, Bruyn GD, Westreich D, Delany-Moretlwe S, Behets F, et al. HIV testing and counseling leads to immediate consistent condom use among South African stable HIV-discordant couples. J Acquir Immune Defic Syndr. 2013;62(2):226.

21. McMahon JM, Pouget ER, Tortu S, Volpe EM, Torres L, Rodriguez W. Couple-Based HIV Counseling and Testing: a Risk Reduction Intervention for US Drug-Involved Women and Their Primary Male Partners. Prev Science. 2015;16:341-351. doi:10.1007/s11121-014-0540-9.

22. Patel SN, Wingood GM, Kosambiya J, McCarty F, Windle M, Yount K, et al. Individual and Interpersonal Characteristics that Influence Male-Dominated Sexual Decision-Making and Inconsistent Condom Use Among Married HIV Serodiscordant Couples in Gujarat, India: Results from the Positive Jeevan Saathi Study. AIDS Behav. 2014;18(10):1970-80.

23. Fonner VA, Denison J, Kennedy CE, O'Reilly K, Sweat M. Voluntary counseling and testing (VCT) for changing HIV-related risk behavior in developing countries. Cochrane Libr. 2012;9:CD001224.

24. McMahon JM, Tortu S, Pouget ER, Torres L, Rodriguez W, Hamid R. Effectiveness of couple-based HIV counseling and testing for women substance users and their primary male partners: a randomized trial. Advances in preventive medicine. 2013;2013:286207.

25. Neme S, Goldenberg T, Stekler JD, Sullivan PS, Stephenson R. Attitudes towards couples HIV testing and counseling among Latino men who have sex with men in the Seattle area. AIDS Care. 2015;27(10):1354-1359. doi:10.1080/09540121.2015.1058894 
26. Kumwenda M, Munthali A, Phiri M, Mwale D, Gutteberg T, MacPherson E, et al. Factors shaping initial decision-making to self-test amongst cohabiting couples in urban Blantyre, Malawi. AIDS Behav. 2014;18(4):396-404.

27. Paiva V, Segurado AC, Filipe EMV. Self-disclosure of HIV diagnosis to sexual partners by heterosexual and bisexual men: a challenge for HIV/AIDS care and prevention. Cadernos de Saúde Pública. 2011;27(9):1699-710.

28. Bachanas P, Medley A, Pals S, Kidder D, Antelman G, Benech I, et al. Disclosure, knowledge of partner status, and condom use among HIV-positive patients attending clinical care in Tanzania, Kenya, and Namibia. AIDS patient care and STDs. 2013;27(7):425-35.

29. Vu L, Andrinopoulos K, Mathews C, Chopra M, Kendall C, Eisele TP. Disclosure of HIV status to sex partners among HIV-infected men and women in Cape Town, South Africa. AIDS Behav. 2012;16(1):132-8.

30. Conserve DF, King G, Dévieux JG, Jean-Gilles M, Malow R. Determinants of HIV serostatus disclosure to sexual partner among HIV-positive alcohol users in Haiti. AIDS Behav. 2014;18(6):1037-45

31. Bärnighausen T, Eyal N, Wikler D. HIV Treatment-as-Prevention Research at a Crossroads. PLoS Med. 2014;11(6):e1001654.

32. Rispel LC, Metcalf CA, Moody K, Cloete A, Caswell G. Sexual relations and childbearing decisions of HIV-discordant couples: an exploratory study in South Africa and Tanzania. Reprod Health Matters. 2011;19(37):184-93.

33. Maina WK, Kim AA, Rutherford GW, Harper M, K'Oyugi BO, Sharif S, et al. Kenya AIDS Indicator Surveys 2007 and 2012: implications for public health policies for HIV prevention and treatment. JAIDS J Acquir Immune Defic Syndr. 2014;66:S130-7.

34. El-Bassel N, Wechsberg WM. Couple-based behavioral HIV interventions: Placing HIV risk-reduction responsibility and agency on the female and male dyad. Couple Fam Psychol: Res Pract. 2012;1(2):94.

35. UBOS. National Population and Housing Census. Republic of Uganda; 2014 31.http://www.ubos.org/onlinefiles/uploads/ubos/NPHC\%2OPROVISIONAL\% 20REPORT.pdf.

36. Field A. Discovering statistics using SPSS. Sage publications; 2009.

37. $\mathrm{MOH}$ U. Addendum to the National Antiretroviral Treatment Guidelines. 2013. http://www.kisiizihospital.org.ug/wp-content/uploadedfiles/2013/10/ addednum-National-ART-Rx-Guidelines-Dec-2013.pdf.

38. Hardon A, Gomez GB, Vernooij E, Desclaux A, Wanyenze RK, Ky-Zerbo O, et al. Do support groups members disclose less to their partners? The dynamics of HIV disclosure in four African countries. BMC Public Health. 2013;13(1):589

39. Deressa W, Seme A, Asefa A, Teshome G, Enqusellassie F. Utilization of PMTCT services and associated factors among pregnant women attending antenatal clinics in Addis Ababa, Ethiopia. BMC Pregnancy Childbirth. 2014;14(1):328.

40. El-Bassel N, Gilbert L, Witte S, Wu E, Hunt T, Remien RH. Couple-based HIV prevention in the United States: advantages, gaps, and future directions. JAIDS J Acquir Immune Defic Syndr. 2010;55:S98-S101.

41. Ellis EM, Homish GG, Parks KA, Collins RL, Kiviniemi MT. Increasing Condom Use by Changing People's Feelings About Them: An Experimental Study. 2015.

42. Dick R, Rink E, FourStar K. The Role of Relationship and Other Factors Associated with Condom Use Intention Among Young American Indian Men Ages 18 to 24 Years Old. J Health Disparities Res Pract. 2015;7(6):5.

43. Matovu JK, Kabanda J, Bwanika JB, Bwayo D, Asingwire N, Kyaddondo D, et al. Determinants of HIV Counseling and Testing Uptake among Individuals in Long-Term Sexual Relationships in Uganda. Curr HIV Res. 2014;12(1):65-73.

44. Matovu JK, Wanyenze RK, Wabwire-Mangen F, Nakubulwa R, Sekamwa R, Masika A, et al. "Men are always scared to test with their partners... it is like taking them to the Police": Motivations for and barriers to couples' HIV counselling and testing in Rakai, Uganda: a qualitative study. J Int AIDS Soc. 2014. 17(1). PMC 4169647. doi: 10.7448/IAS.17.1.19160

45. Lépine A, Terris-Prestholt F, Vickerman P. Determinants of HIV testing among Nigerian couples: a multilevel modelling approach. Health Policy Plan. 2014:30(5):579-592. doi: 10.1093/healpol/czu036

46. De Schacht C, Hoffman HJ, Mabunda N, Lucas C, Alons CL, Madonela A, et al. High rates of HIV seroconversion in pregnant women and low reported levels of HIV testing among male partners in southern Mozambique: Results from a mixed methods study. PLoS One. 2014;9(12):e115014.

47. Rujumba J, Neema S, Byamugisha R, Tylleskär T, Tumwine JK, Heggenhougen HK. "Telling my husband I have HIV is too heavy to come out of my mouth": pregnant women's disclosure experiences and support needs following antenatal HIV testing in eastern Uganda. J Int AIDS Soc. 2012;15(2):17429.
48. Njau B, Watt M, Ostermann J, Manongi R, Sikkema K. Perceived acceptability of home-based couples voluntary HIV counseling and testing in Northern Tanzania. AIDS care. 2012;24(4):413-9.

49. Dalal W, Feikin DR, Amolloh M, Ransom R, Burke H, Lugalia F, et al. Homebased HIV testing and counseling in rural and urban Kenyan communities. JAIDS J Acquir Immune Defic Syndr. 2013;62(2):e47-54.

50. van Rooyen H, Barnabas RV, Baeten JM, Phakathi Z, Joseph P, Krows M, et al. High HIV testing uptake and linkage to care in a novel program of home_ based HIV counseling and testing with facilitated referral in KwaZulu-Natal, South Africa. J Acquir Immune Defic Syndr. 2013;64(1):e1.

51. Tabana H, Doherty T, Swanevelder S, Lombard C, Jackson D, Zembe W, et al. Knowledge of HIV status prior to a community HIV counseling and testing intervention in a rural district of South Africa: results of a community based survey. BMC Infect Dis. 2012;12(1):73.

52. Sekandi JN, Sempeera H, List J, Mugerwa MA, Asiimwe S, Yin X, et al. High acceptance of home-based HIV counseling and testing in an urban community setting in Uganda. BMC Public Health. 2011;11(1):730.

53. Fylkesnes K, Sandøy IF, Jürgensen M, Chipimo PJ, Mwangala S, Michelo C. Strong effects of home-based voluntary HIV counselling and testing on acceptance and equity: a cluster randomised trial in Zambia. Soc Sci Med. 2013:86:9-16.

54. Darbes L, Chakravarty D, Leddy A, Dladla S, de Bruyn G. Sexua Communication Self-Efficacy (SCSE) is a Significant Predictor of Participating in Couples-Based Voluntary Counseling and Testing (CBVCT) for HIV in Soweto. IAC Washington DC 2012. http://ari.ucsf.edu/science/posters_2012/ 2012\%20IAC\%20posters/darbes IAC2012.pdf

55. Orne-Gliemann J, Balestre E, Tchendjou P, Miric M, Darak S, Butsashvili M, et al. Increasing HIV testing among male partners. Aids. 2013;27(7):1167-77.

56. Brown B, Folayan MO, Imosili A, Durueke F, Amuamuziam A. HIV self-testing in Nigeria: Public opinions and perspectives. Global Public Health. 2014; 10(3):1-12. doi: 10.1080/17441692.947303

57. Stephenson R, Rentsch C, Sullivan P, McAdams-Mahmoud A, Jobson G, Struthers $\mathrm{H}$, et al. Attitudes toward couples-based HIV counseling and testing among MSM in Cape Town, South Africa. AIDS Behav. 2013;17(1):43-50.

\section{Submit your next manuscript to BioMed Central and we will help you at every step:}

- We accept pre-submission inquiries

- Our selector tool helps you to find the most relevant journal

- We provide round the clock customer support

- Convenient online submission

- Thorough peer review

- Inclusion in PubMed and all major indexing services

- Maximum visibility for your research

Submit your manuscript at www.biomedcentral.com/submit 